\title{
KONFLIKTY ZBROJNE W PRADZIEJACH. PERSPEKTYWY BADAWCZE
}

\section{ARMED CONFLICTS IN THE PAST. RESEARCH PERSPECTIVES}

\author{
Rafat Skrzyniecki
}

Instytut Prahistorii, Uniwersytet im. Adama Mickiewicza

ul. Św. Marcin 78, 61 - 809 Poznań, Poland

\begin{abstract}
The main issue of this article is to discuss the history and state of the arts of warfare and violence in prehistoric Europe and present crucial categories of archaeological finds related to this kind of past human activity. Organized violence undoubtedly played an important role in the existence of prehistoric people and is also considered as one of the main factors responsible for changes in culture of past societies. Moreover, relatively large number/quantity of archaeological data and a constantly growing number of studies relating to warfare clearly shows, that this interesting issue by no means should be ignored and deserves researchers' attention.
\end{abstract}

Władza, dominacja i przymus to kwestie nierozerwalnie związane z wojną i jej głównymi aktorami, tj. wojownikami i żołnierzami. Wojna jest jednym z głównych czynników generujących zmiany w kulturze, zarówno na poziomie społecznym, jak i materialnym. Wywiera również istotny wpływ na egzystencję ludzi niemal w każdym zakątku współczesnego świata. Patrząc wstecz można jednak odnieść wrażenie, że archeolodzy w XX w. badali jedynie wyselekcjonowane aspekty konfliktów zbrojnych, np. uzbrojenie czy wojowników, nie zagłębiając się przy tym w sedno sprawy: w samą naturę wojny (jej początki, przyczyny, charakter, przebieg itd.).

\section{HISTORIA BADAŃ NAD PROBLEMEM WOJEN I PRZEMOCY W PRADZIEJACH}

Archeologia XX w., pomimo stosunkowo bogatej bazy źródłowej związanej z wojną i przemocą, przeważnie ignorowała wszelkie dowody na istnienie konfliktów w pradziejach ${ }^{1}$. Niezależnie od obowiązujących w danym czasie paradygmatów

${ }^{1}$ Vencl 1984; Vandkilde 2003, 2006, 2013. 
badawczych kształtowały się dwa rozbieżne w swojej wymowie podejścia do omawianego problemu. $\mathrm{Z}$ czasem dały one początek dwóm wyraźnie nakreślonym stereotypom, determinującym charakter oraz przebieg dyskusji akademickich dotyczących konfliktów zbrojnych w pradziejach. Zdaniem niektórych badaczy popularność tych nurtów była ściśle sprzężona $\mathrm{z}$ rejestrowaną $\mathrm{w}$ danym czasie sytuacją polityczno-ideologiczną ( $w$ tym również studiami nad gender czy konfliktami zbrojnymi). Przyjmuje się, że początki tej dychotomii sięgają XVII w. i są zakorzenione w dwóch mitach o naturze przysłowiowego „dzikiego”, po dziś dzień inspirujących przedstawicieli nauk społecznych z całego świata ${ }^{2}$.

Pierwsze próby konceptualizacji problemu wojen i przemocy datuje się na XVII stulecie. Wtedy to angielski filozof, Thomas Hobbes, na kartach swojego dzieła Leviathan przedłożył ówczesnym swoją sugestywną wizję początków ludzkości. Jego zdaniem dominującym elementem ludzkiej natury była przemoc - dzika i nieskrępowana, znajdująca ujście w stanie permanentnej, anarchicznej „,wojny wszystkich przeciw wszystkim". Dopiero nadejście kultury wraz z jej uniwersalnymi prawami położyło kres temu autodestrukcyjnemu konfliktowi o globalnym zasięgu. Symbolicznym zerwaniem więzi z naturą, utożsamianą ze zwierzęcymi instynktami, ciemiężącymi kiełkujące w ludziach człowieczeństwo, było zawarcie powszechnego przymierza, na mocy którego wyłoniona została władza zwierzchnia, będąca gwarantem ładu i bezpieczeństwa ${ }^{3}$. Powołanie do istnienia nowej instytucji społecznej oraz przyznanie jej prawa do użycia przemocy jako narzędzia do obrony uciśnionych oraz karania niegodziwych zamknęło mroczny etap dziejów człowieka i pchnęło go na drogę rozwoju kulturowego, którą podąża po dziś dzień ${ }^{4}$.

Przeszło wiek po Hobbesie głos w sprawie początków ludzkości zabrał francuski myśliciel Jan Jakub Rousseau. W przeciwieństwie do swego poprzednika przekonywał, że ludzkość systematycznie dąży do autodestrukcji spowodowanej zerwaniem pierwotnej więzi z przyrodą oraz przyjęciem praw kulturowych, wypaczających prawdziwą naturę człowieka. Według Rousseau pierwsi ludzie wiedli idylliczny żywot w krainie będącej odpowiednikiem biblijnego Edenu. Obce im były spory, głód i przemoc. Do upadku utopii doprowadziła, inaczej niż u Hobbesa, kultura. Rozbudziła ona w ludziach zachłanność i nieokiełznaną żądzę posiadania. Chęć szybkiego wzbogacenia się kosztem innego człowieka nierzadko popychała ludzi do przemocy, a w dalszej konsekwencji do wojen. Posługując się starannie dobranymi przykładami społeczeństw etnograficznych, Rousseau przekonywał, że ludy nieobeznane z cywilizacją wiodą sielankowy, dostatni żywot i gardzą przemocą ${ }^{5}$. Były to zatem dwie zupełnie odmienne koncepcje, obie jednak wywarły znaczący wpływ na

\footnotetext{
${ }^{2}$ Vandkilde 2003, 2006.

${ }^{3}$ Hobbes 1954.

${ }^{4}$ Hobbes 1954.

${ }^{5}$ Gat 2005, 5, 6 .
} 
przebieg późniejszej debaty archeologicznej, poświęconej problemowi wojen i przemocy w pradziejach.

Zakorzeniony w świadomości akademików mit o ,prymitywnym obcym”, a raczej dwie opozycyjne koncepcje filozoficzne, konstytuujące ów mit, wywarły znamienny wpływ na charakter dwudziestowiecznej debaty archeologicznej, poświęconej problematyce wojen $\mathrm{w}$ pradziejach ${ }^{6}$. Teoretycznym spoiwem obu jest (odmienne) pojmowanie społeczeństwa oraz zespół czynników odpowiedzialnych za inicjację i charakter procesu zmiany społecznej. Pierwszy nurt przypisuje (z reguły jednak w dość „zawoalowany” sposób) pewne znaczenie postaciom wojowników, społeczeństwo natomiast ujmuje jako niestabilny twór podatny na nagłe, nierzadko radykalne zmiany, dokonujące się za sprawą ludzkiej sprawczości (human agency). Z kolei trend drugi, późniejszy, przywołuje idylliczną wizję pradziejowego świata wolnego od przemocy, zasiedlonego przez chłopów, myśliwych i kupców. Społeczeństwo postrzega jako twór podlegający powolnej ewolucji, dokonującej się w ramach społecznej reprodukcji wzorców utrwalonych w kulturze ${ }^{7}$.

Pierwsza z nakreślonych powyżej tradycji badawczych nabierała kształtów na kartach prac V.G. Childe’a i współczesnych mu przedstawicieli szkoły empirycznej. Mimo wyraźnego sentymentu dla postaci wojowników, Childe niechętnie uznawał wojnę za jedną z sił sprawczych historii. W swoich późniejszych pracach często jednak sięgał po tematykę warfare, stosując ów termin niczym słowo-wytrych, pomocne w opisywaniu ekonomicznej chciwości pradziejowej arystokracji ${ }^{8}$. W podobny sposób problematykę konfliktów zbrojnych przedstawiał w swoich pracach P.V. Glob. Być może pozostając pod przemożnym wpływem piśmiennictwa Childe'a, rozpościerał on przed swoimi adherentami perswazyjne, by nie rzec: romantyczne wizje konnych wojowników-nomadów, zbrojnych w topory kamienne, reprezentujących w jego mniemaniu przedstawicieli kultury toporów bojowych"

Podobną tendencję można zaobserwować w pracach archeologów z przełomu lat 70. i 80. XX w., reprezentujących nurt strukturalno-marksistowski. Ich narracja miała wymiar w znacznym stopniu zbliżony do childowskiej, choć wysuwane dotychczas na pierwszy plan pojęcie migracji zastąpiły wewnętrzna dynamika społeczna i strukturalne opozycje, uznawane od tej pory za przyczynę nagłych zmian o charakterze społecznym.

Mimo że model migracji i rewolucji nie uwzględnia pokojowej interakcji, jego retoryka rzadko sięga po wojnę i przemoc. Zamiast nich posługuje się niekiedy miękkimi metaforami, takimi jak np. „,niespokojne czasy”. Wciąż jednak istota problemu, tj. wojna, funkcjonuje na bardzo odległym planie, nawet nie tyle w charakte-

\footnotetext{
${ }^{6}$ Keeley 2006; Chapman 1999.

${ }^{7}$ Vandkilde 2003, 2006.

${ }^{8} \mathrm{~Np}$. Childe 1946, 42; 1951a, 108, 109; 1951b, 62, 92.

${ }^{9}$ Vandkilde 2003, 2006.
} 
rze perswazyjnego tła, ile raczej nieistotnej błyskotki. W nielicznych pracach wzmiankujących o warfare podkreśla się funkcje społeczne walki, która jest przedstawiana jest jako klucz do awansu społecznego ${ }^{10}$. Przeważnie ma ona jednak bezkrwawy, teatralny wymiar. Jest to zatem wyidealizowany obraz wojny, odarty z jej kardynalnej składowej - przemocy, która z piedestału zajmowanego przez słowa-klucze została zepchnięta na marginesy zapisywane luźnymi refleksjami i zredukowana do roli nieistotnej wzmianki.

Swoisty wyjątek od reguły stanowią prace Marii Gimbutas - amerykańskiej badaczki litewskiego pochodzenia, zajmującej się tematyką gender oraz problemem zmiany społecznej w pradziejach. Według niej kres protocywilizacjom eneolitycznym z obszaru międzymorza miał przynieść najazd kultur kurhanowych ze wschodu, reprezentujących nowy, patriarchalny ład społeczny oraz gloryfikujących pierwiastki męskie ${ }^{11}$. Propozycja ta nie znalazła solidnego oparcia w bazie źródłowej i była często krytykowana, niemniej jednak otwierała nowy wątek w ówczesnej debacie archeologicznej, gdyż wskazywała na wojnę jako istotny czynnik kształtujący sytuację kulturową w Europie Południowo-Wschodniej w epoce miedzi.

Odwrotny trend upowszechnił się na przełomie lat 40. i 50. XX w. Wojowników zastąpili wzmiankowani już rolnicy, myśliwi i kupcy. Punkt ciężkości badań przeniesiono z popularnych dotychczas migracji i rewolucji na kwestie związane z gospodarką wytwórczą. Ta nowa perspektywa badawcza upowszechniła się m.in. dzięki pracom Grahama Clarke'a. Interesowały go przede wszystkim kwestie środowiskowe oraz funkcja kultury. Zdecydowanie mniej uwagi poświęcał problemowi zmiany kulturowej, co stało w jawnej opozycji wobec retoryki marksistowskiej czytelnej w dziełach Childe'a ${ }^{12}$. W ujęciu Clarka i Piggota wczesny neolit należałoby uznać za czas funkcjonowania stabilnych społeczności wieśniaczych, natomiast epoka brązu to czas kupców i dynamicznie rozwijającego się przemysłu metalurgicznego $^{13}$. Przedstawiciele Nowej Archeologii centralnym punktem swoich rozważań uczynili problem zmiany społecznej, rozpatrywanej w kategoriach powoli dokonującej się ewolucji. Ich poglądy w znacznej mierze ukształtowały się pod wpływem neoewolucjonizmu, funkcjonującego $\mathrm{w}$ antropologii kulturowej od drugiej połowy lat 40. XX w. Neoewolucjonizm zakładał powolny, niezakłócony rozwój społeczności pradziejowych, tożsamy z postępującą komplikacją struktur społecznych. Nagłe, radykalne zmiany dokonywały się rzadko, z reguły wskutek niesprzyjających warunków środowiskowych bądź przeludnienia. Stąd, w ujęciu zwolenników omawianej opcji interpretacyjnej, reprodukcja utrwalonych wzorców społecznych była czymś naturalnym i stanowiła dominujący schemat rozwoju. Pogląd ten konse-

\footnotetext{
${ }^{10} \mathrm{~Np}$. Treherne 1995; Kristiansen, Larsson 2005.

${ }^{11}$ Gimbutas 1982.

${ }^{12}$ Vandkilde 2006.

${ }^{13}$ Clark, Piggot 1978.
} 
kwentnie podtrzymywano nawet wówczas, gdy badania etnograficzne wykazały, że wojna jest permanentną częścią życia większości społeczności przedpaństwowych. Egzemplarzom pradziejowej broni arbitralnie przypisywano symboliczne znaczenie, czyniąc z nich podstawowy element wymiany darów między członkami społeczności cieszącymi się wysokim statusem społecznym. Omawiany stan rzeczy można w pewnym stopniu tłumaczyć wpływem, jaki ówczesna sytuacja polityczno-ideologiczna wywarła na charakter powojennego dyskursu archeologicznego. Widmo dopiero co zakończonego konfliktu światowego wciąż kładło się cieniem na świadomości ówczesnych. Wielu ludzi nadal dręczyły przerażające wspomnienia, nierzadko podszyte doświadczonym cierpieniem natury zarówno fizycznej, jak i psychicznej. Koniec wojny zaszczepiał jednak w ich sercu nadzieję na lepszą przyszłość, popartą dodatkowo realną perspektywą odbudowy zatraconego ładu, poprawy warunków bytowych i życia w pokoju. Zmęczone i wykrwawione społeczeństwo pragnęło stabilizacji, w związku z czym akceptowało dokonujące się zmiany. Znalazło to odbicie między innymi w pracach ówczesnych archeologów ${ }^{14}$.

Od lat 80 . XX w. notuje się postępujący wzrost zainteresowania problematyką wojen i przemocy w pradziejach. $Z$ tego okresu pochodzą prace wskazujące możliwości i ograniczenia związane z omawianym zagadnieniem. Swoisty manifest archeologii warfare pt. „War and Warfare in Archaeology” opublikował w pierwszej połowie lat 80. Slavomil Vencl ${ }^{15}$. W przywołanym artykule omówił on m.in. zjawisko niewielkiego zainteresowania problematyką warfare $\mathrm{w}$ archeologii. Jego zdaniem podstawową przyczyną takiego stanu rzeczy jest charakter oraz dostępność materialnych świadectw „wojen” prowadzonych przez pradziejowe społeczności przedpiśmienne. Vencl przyjął, że wojna to praktyka społeczna silnie związana z dyskursem władzy, a więc aspektem ludzkiej działalności generującym niewielką liczbę materialnych pozostałości. Nie ulega wątpliwości, że specyfika materii źródłowej stwarza pewne ograniczenia, prowadzące do zaniżenia liczby znalezisk bezpośrednio związanych z warfare (traumata, broń wykonana $\mathrm{z}$ surowców organicznych). Problem nieuchwytności określonych kategorii znalezisk archeologicznych, które można by było z dużym prawdopodobieństwem uznać za związane z wojną i konfliktami zbrojnymi, doprowadził (oprócz innych czynników omówionych w poprzednim podrozdziale) do wyłączenia zagadnienia warfare z puli dostępnych teorii thumaczących zmiany kulturowe. W sytuacji gdy archeologia nie dysponowała materialnymi dowodami na to, że w pradziejach rzeczywiście dochodziło do konfliktów, rejestrowane na stanowiskach archeologicznych broń, groby wojowników i fortyfikacje obdzierano z ich pierwotnego znaczenia i odgórnie wpisywano w odmienny kontekst, najczęściej nadając im status przedmiotów/obiektów o charakterze kultowym ${ }^{16}$.

\footnotetext{
${ }^{14}$ Vandkilde 2003, 2006, 2013.

${ }^{15}$ Vencl 1984

${ }^{16}$ Vencl 1984, 123.
} 
Slavomil Vencl zaproponował poszerzenie procedury badawczej o refleksję nad kategoriami źródeł, które składały się na obraz badanego wycinka przeszłości, niemniej jednak z różnych przyczyn nie dotrwały do naszych czasów w namacalnej postaci. Zasadniczego znaczenia nabrał w tej sytuacji kontekst znaleziska, nie zawsze uchwytny archeologicznie, aczkolwiek obfitujący w informacje niezbędne do uczynienia kreowanych interpretacji bardziej wiarygodnymi i zrozumiałymi. Aby dotrzeć do zawartej w kontekście puli danych, należy położyć większy nacisk na rozpoznanie i zrozumienie perspektywy historycznej, stojącej za analizowanym materiałem. Archeologiczne badania koncentrujące się na problematyce warfare powinny więc stanowić istotny element szerszych studiów nad pradziejami. Tworzenie wiarygodnych i kompletnych interpretacji jest możliwe jedynie z perspektywy badań interdyscyplinarnych. Priorytetem jest więc powtórne wdrożenie dostępnego materiału archeologicznego we właściwy mu kontekst. „Przywracanie” kontekstu, tj. swoista „reintegracja” dostępnych informacji, wymaga bowiem uwzględnienia szerokiego spektrum danych z zakresu antropologii fizycznej i kulturowej, historii oraz nauk przyrodniczych ${ }^{17}$.

Postulowana przez Vencla konieczność prowadzenia badań interdyscyplinarnych nadal zachowuje aktualność, jednak w związku z rejestrowanym w ciągu ostatnich dwudziestu lat znacznym przyrostem materii źródłowej część z jego zastrzeżeń można obecnie uznać za anachronizmy. Liczba egzemplarzy pradziejowego oręża oraz odkrytych fortyfikacji jest znaczna. Pulę uzupełniają dodatkowo malowidła i ryty naskalne, obrazujące starcia zbrojne i sceny egzekucji. Również zgromadzone dotychczas traumata (uszkodzenia szkieletów powstałe w wyniku przemocy) stanowią dość pokaźny zbiór, jeśli weźmie się pod uwagę, że:

- kości ludzkie często zachowują się w słabym stopniu,

- szkielety rzadko poddaje się badaniu na obecność śladów przemocy,

- tylko niewielki odsetek ran pozostawia ślady na tkance kostnej.

Prawdziwa moda na archeologię warfare przypadła na lata $90 . \mathrm{XX} \mathrm{w.}{ }^{18}$. Warto zaznaczyć, że ta istotna reorientacja zainteresowań badawczych zdaniem niektórych teoretyków dokonała się niezależnie i nie miała żadnego związku z przypadającym na lata 80. XX w. ,złotym wiekiem” antropologii wojny ${ }^{19}$. Co więcej, mimo wielu punktów wspólnych, w ciągu ostatnich stu lat obie dyscypliny przenikały się i korespondowały ze sobą na omawianym polu w niewielkim tylko stopniu. Gdzie zatem należy doszukiwać się przyczyn tak radykalnego wzrostu zainteresowania problemem wojen i konfliktów zbrojnych w pradziejach? Zdaniem Helle Vandkilde charakter ogólnoświatowej debaty archeologicznej jest wyraźnie sprzężony z rejestrowaną $\mathrm{w}$ danym momencie historii sytuacją społeczno-ideologiczno-polityczną.

\footnotetext{
${ }^{17}$ Vencl 1984, 118, 119.

${ }^{18}$ Keeley 1996; Carman, Harding 1999.

${ }^{19}$ Vandkilde 2003.
} 
Badaczka ta przypomina, że uwaga wszystkich mieszkańców Europy w połowie lat 90. XX w. koncentrowała się na brutalnych wojnach etnicznych, które rozgorzały wówczas na Bałkanach. Obrazy przemocy, bólu i cierpienia nieustannie przewijały się we wszystkich mediach, nieuchronnie bombardując świadomość zarówno laików, jak i przedstawicieli środowisk naukowych z archeologami włącznie ${ }^{20}$.

\section{WOJNA I PRZEMOC W PRADZIEJACH. DEFINICJA WOJNY, KATEGORIE ZABYTKÓW - WYBRANE PRZYKŁADY}

\section{Definicja „,wojny” w kontekście pradziejów}

W celu uniknięcia nieporozumień terminologicznych wywód na temat wojen i przemocy w pradziejach należy rozpocząc od próby zdefiniowania omawianego zjawiska. W archeologii pojęcie to funkcjonuje w odniesieniu do małych społeczności, najczęściej o charakterze rodowym, badanych wyłącznie za pośrednictwem źródeł archeologicznych ${ }^{21}$. W takim ujęciu warfare należy rozumieć jako odgórnie zaplanowaną konfrontację dwóch lub więcej grup ludzkich, reprezentujących odmienne tradycje i zajmujących odrębne terytoria; ma ona brutalny przebieg i niejednokrotnie prowadzi do śmierci jej uczestników. Jest to przy tym zajęcie usankcjonowane kulturowo, stanowi bowiem jeden ze sposobów zabezpieczenia interesów grupy. Należy jednak zaznaczyć, że archeologia nie wypracowała jak dotąd metod badawczych, które pozwoliłyby na rozpoznanie i opisanie takich aspektów wojny, jak np. etap przygotowań do starcia, jego przebiegu czy motywacja osób biorących w nim udział. Odpowiedzi na powyższe pytania może dostarczyć antropologia kulturowa, najczęściej na drodze analogii. Jest to jednak ryzykowna metoda wnioskowania. Nieprzemyślana aplikacja rozwiązania ,wyszarpanego” z odmiennego kontekstu często prowadzi do fałszywych wniosków. W stosowaniu analogii międzykulturowych należy zatem zachować szczególną ostrożność.

W polskim piśmiennictwie naukowym terminy warfare i war tłumaczy się często tak samo - wojna. W odniesieniu do społeczeństw przedpiśmiennych termin „wojna” jest jednak brany w cudzysłów, gdyż określa zjawisko odmienne od konfliktu we współczesnym znaczeniu tego słowa. T. Buliński i M. Kairski zaznaczają wręcz, że zdecydowanie łatwiej opracować definicję negatywną „,wojny”, wymieniając po prostu, czym to zjawisko nie jest, aniżeli ustalić jego ścisły zakres znaczeniowy. Na podstawie ustaleń antropologii kulturowej udało się określić pewne minimum cech definiujących wojnę w jej ujęciu ogólnym (niezależnie od stopnia rozwoju jednostek kulturowych biorących w niej udział). Jest to zatem ,przedsię-

\footnotetext{
${ }^{20}$ Vandkilde 2003.

${ }^{21}$ Millner 1999.
} 
wzięcie grupowe, skierowane na zewnątrz, przeciwko innej grupie ludzi, nie tylko przeciw pojedynczym osobom lub ich rodzinom, ale przeciw członkom całej wspólnoty, tym, którzy będą uzbrojeni, wykażą wolę użycia broni lub będą stawiać opór "22. Celem tego przedsięwzięcia jest „ppozbawienie życia członków zaatakowanej wspólnoty (...)" lub przynajmniej branie pod uwagę potencjalnych skutków śmiertelnych działań ${ }^{23}$. Jak widać, definicja ta nie uwzględnia jednostkowych zabójstw oraz tzw. wypraw odwetowych, podyktowanych zwyczajem „krwawej zemsty". Działania tego typu zalicza się raczej do warfare. Z socjologicznego punktu widzenia wojna we współczesnym znaczeniu tego słowa to konflikt zbrojny między co najmniej dwiema zgeneralizowanymi zbiorowościami, natomiast warfare odnosi się również do sporów między pojedynczymi jednostkami i grupami krewniaczymi. Refleksję nad definicją „,wojny” warto jeszcze uzupełnić o propozycję Kelly'ego ${ }^{24}$, wykorzystaną przez Mirjanę Roksandic do interpretacji przejawów przemocy z mezolitycznego stanowiska Schela Cladovei w rejonie Żelaznych Wrót ${ }^{25}$. Według Kelly'ego ${ }^{26}$ jednym z elementów konstytuujących warfare jest zjawisko „Zastępowalności społecznej" (social substitutability). Jest to zasada, w duchu której każdy członek danej grupy może być zastąpiony innym jej członkiem. Odnosi się do sytuacji, gdy grupa poszkodowana szuka pomsty za zadane jej krzywdy. Ofiarą zemsty nie pada winowajca, lecz pierwsza napotkana osoba (lub wiele osób) przynależąca do grupy, z której wywodzi się winny. Materialnym przejawem funkcjonowania owej zasady jest obecność uszkodzeń na szkieletach kobiet i dzieci, siłą rzeczy przeważnie niezdolnych do zranienia lub zabicia przeciwnika. Występowanie traumata w kontekście pochówków żeńskich i dziecięcych pozwala, zdaniem Roksandic, oddzielić przejawy warfare od aktów przemocy związanych z morderstwami, pojedynkami czy generalnie pojętą karą za popełnione przewinienia, ponieważ we wszystkich tych przypadkach ofiarą najczęściej pada sam winny. Powyższe rozważania warto zakończyć stwierdzeniem T. Bulińskiego i M. Kairskiego ${ }^{27}$, określającym fenomen warfare jako ,działanie, które nie uległo optymalizacji i racjonalizacji zgodnie z nowożytnym rozumieniem tych terminów. Wystarczy uznać go (fenomen warfa$r e$ - przyp. R.S.) za dawną formę przemocy; formę, którą jeszcze parę wieków temu znały także społeczności europejskie. Symbolem tego dawnego świata niech będzie chociażby śmierć na polu bitwy pod Crécy niewidomego Jana Luksemburskiego w roku 1346, w czasie wojny stuletniej. Aby zrozumieć motywy jego decyzji i okoliczności jego śmierci, raczej należy odwołać się do koncepcji warfare niż do nowożytnego, zracjonalizowanego modelu wojny".

\footnotetext{
${ }^{22}$ Buliński, Kairski 2006

${ }^{23}$ Buliński, Kairski 2006.

${ }^{24}$ Kelly 2000.

${ }^{25}$ Roksandic 2006.

${ }^{26}$ Roksandic 2006.

${ }^{27}$ Buliński, Kairski 2006.
} 


\section{Kategorie zabytków związanych z warfare}

Na obecnym etapie refleksji nad problemem ,wojen” i przemocy w pradziejach wyróżnia się cztery kategorie znalezisk uznawanych za ich materialne świadectwa. Są to: egzemplarze i przedstawienia broni; występowanie konstrukcji obronnych w osadach; uszkodzenia szkieletów; groby wojowników. W swoim artykule „Warfare and the evolution of culture" Jonathan Haas zaproponował rozszerzoną wersję podziału, zawierającą szczegółowe rozwinięcie wyróżnionych kategorii zabytków ${ }^{28}$. Prezentuje się ona następująco:

Ślady na kościach (traumata):

Parry fractures - uszkodzenia kości przedramion

Pęknięcia na czaszkach

Nacięcia po skalpowaniu

Groty strzał i oszczepów tkwiące w kościach

Osadnictwo:

Palisady

Fortyfikacje

Osady obronne (ulokowane w trudno dostępnych miejscach)

Punkty obserwacyjne

Obrządek pogrzebowy:

Groby masowe

Groby wojowników

Zmniejszona liczba dorosłych osobników płci męskiej rejestrowana w obrębie cmentarzysk

Sztuka:

Ryty, malowidła naskalne

Przedstawienia na ceramice

\section{Uszkodzenia szkieletów}

Najstarsze poświadczone uszkodzenia kośćca związane z użyciem przemocy pochodzą ze środkowego paleolitu i związane są z Neandertalczykami. Na szkielecie z Mugharet es Skhul rozpoznano ubytek kostny na jednym z żeber, stanowiący zdaniem specjalistów ślad po ranie zadanej długim, ostrym przedmiotem - najprawdopodobniej włóczni. Morfologia ubytku wskazuje ponadto, że wskutek ciosu mogło dojść do uszkodzenia płuca, a w konsekwencji do śmierci osobnika. Niektórzy eksperci utrzymują, że na ponad $40 \%$ przebadanych dotąd czaszek Neandertalczyków

\footnotetext{
${ }^{28}$ Haas 1998.
} 
widnieją wyraźne ślady uszkodzeń. Zdaniem Brothwella ${ }^{29}$ stan ten nie jest dziełem przypadku i stanowi poważną przesłankę o angażowaniu się populacji neandertalskich w konflikty. Jedna z bardziej wiarygodnych hipotez tłumaczących wysoki odsetek ofiar przemocy wśród homo sapiens neanderthalensis wskazuje, że większość rozpoznanych ran powstała wskutek kontaktu z agresywną zwierzyną łowną. Neandertalczycy nie znali bowiem broni miotanej, w związku z czym zmuszeni byli polować za pomocą masywnych włóczni o ciężkich grotach z krzemienia. Taka taktyka łowiecka wiązała się z koniecznością zbliżenia się do zwierzyny, co stwarzało poważne ryzyko odniesienia uszczerbku na zdrowiu. Namacalnym świadectwem tegoż ryzyka są właśnie uszkodzenia czaszek i kręgów szyjnych powszechnie występujące na szkieletach neandertalskich ${ }^{30}$.

Radykalny wzrost liczby traumata odnotowuje się wraz z początkiem mezolitu. Wiąże się to w dużej mierze ze zmianami klimatycznymi zachodzącymi u progu holocenu; ocieplenie klimatu i wzrost wilgotności sprzyjały rozwojowi obszarów leśnych, zamieszkiwanych przez bardziej osiadłe gatunki zwierzyny łownej. Adaptujące się do nowych warunków populacje ludzkie porzuciły sezonowe wędrówki za stadami na rzecz relatywnie stabilnego osadnictwa, związanego z eksploatacją zasobnych terytoriów łowieckich. Wzrost zasiedziałości tych grup zaowocował wykształceniem się więzi z zajmowanym obszarem, czego materialnym dowodem są pierwsze cmentarzyska ${ }^{31}$. Pełniły one dwojaką funkcję - z jednej strony służyły jako pola grzebalne, $z$ drugiej natomiast manifestowały obecność i wyłączne prawo grupy do zasiedlania i korzystania z zasobów określonego terytorium. Część badaczy uważa, że postępujące zjawisko „terytorializmu” (tj. przywiązania do ziemi) stało się zarzewiem pierwszych konfliktów ${ }^{32}$. Mimo znacznej liczby szkieletów noszących ślady uszkodzeń przyjmuje się, że przemoc $\mathrm{w}$ mezolicie miała charakter lokalny i epizodyczny, i nie wywarła większego wpływu na sytuację społeczno-kulturową omawianego okresu ${ }^{33}$.

Ogromna liczba materiałów kostnych w typie skeletal traumata pochodzi z neolitu. L. Keeley i M. Golitko ${ }^{34}$ uważają, że ślady przemocy czytelne są na ponad $20 \%$ szkieletów przedstawicieli młodszych faz kultury ceramiki wstęgowej z jej zachodniej ekumeny. Hipoteza ta mocno kontrastuje z obowiązującym dotychczas przekonaniem, że społeczności pierwszych rolników były pokojowo usposobione i koncentrowały się przede wszystkim na trudnej sztuce uprawy ziemi. Należy przy tym pamiętać, że omawiana kategoria znalezisk związanych z „wojną” jest bardzo czuła na działanie procesów podepozycyjnych, co często prowadzi do zatarcia śladów na

\footnotetext{
${ }^{29}$ Brothwell 1999.

${ }^{30}$ Thorpe 2005.

${ }^{31}$ Vencl 1984.

${ }_{32}^{32}$ Np. Vencl 1984, 1999; Roksandic 2006.

${ }^{33}$ Thorpe 2005; Haas 1998; Roksandic 2006.

${ }^{34}$ Keeley, Golitko 2006.
} 
kośćcu $^{35}$. Ponadto starsze opracowania materiałów kostnych zazwyczaj nie uwzględniały analiz szkieletów pod kątem obecności uszkodzeń. Co więcej, zaledwie 30\% ran pochodzących od strzał ,zachowuje się” w postaci ubytków kostnych, gdyż zdecydowana ich większość wiąże się z penetracją tkanek miękkich ${ }^{36}$. Biorąc pod uwagę wymienione czynniki, można z pewną dozą ostrożności przyjąć, że realna liczba ofiar konfliktów była zdecydowanie wyższa. Uwaga ta odnosi się nie tylko do neolitu, lecz także do epok późniejszych.

\section{Groby masowe}

Gros materiałów kostnych ze śladami uszkodzeń pochodzi z grobów masowych. Pojawiają się one już $w$ neolicie. Jednym $z$ najlepiej przebadanych jest obiekt z miejscowości Talheim (Niemcy), datowany na 5000 BC i związany z tradycją kultury ceramiki wstęgowej. Natrafiono w nim na szczątki 34 osobników w różnym wieku: 16 młodocianych oraz 18 dorosłych, z czego dziewięć szkieletów należało do mężczyzn, siedem do kobiet, a w dwóch przypadkach płci nie udało się określić. Od 18 do 20 czaszek nosiło ślady śmiertelnych ran. Układ szkieletów wskazywał na niedbałość i pośpiech towarzyszący pochówkowi. Wygląda na to, że zmarłych wrzucono do naprędce wykopanej jamy, nie troszcząc się o zachowanie reguł obrządku pogrzebowego. Na większości czaszek uszkodzenia wystąpiły w okolicach potylicy. Odkrywcom grobu udało się nawet dopasować kształt pęknięć do kamiennych głowic narzędzi używanych przez społeczności kultury ceramiki wstęgowej. Dwoje osobników zmarło wskutek ran od strzał. Uszkodzeń nie stwierdzono natomiast na kościach ramion. Na jednej z czaszek, należącej do dorosłego mężczyzny, oprócz pozostałości po śmiertelnej ranie stwierdzono ślady wcześniejszego, zagojonego uszkodzenia. Prawdopodobnie ten mężczyzna brał wcześniej udział w walkach - nie wiadomo jednak, czy w charakterze obrońcy, czy napastnika. Liczba ofiar i charakter ich obrażeń wskazuje na zorganizowany atak i eksterminację całej populacji $\operatorname{osady}^{37}$.

Niezwykle interesującego odkrycia dokonano również w trakcie eksploracji neolitycznego enclosure w miejscowości Schletz (Austria). Prace wykopaliskowe, prowadzone na odcinku głębokiego na dwa metry rowu, odsłoniły szczątki przeszło 70 osobników, z czego 67 zginęło wskutek uderzenia w głowę ciężkim narzędziem obuchowym. Żaden ze zmarłych nie został pochowany zgodnie z regułami obrządku pogrzebowego. Część ciał padła ofiarą drapieżników, o czym świadczą charakterystyczne ślady miażdżenia widoczne na kościach. Najprawdopodobniej zwłoki po-

\footnotetext{
${ }^{35}$ Vencl 1984.

${ }^{36}$ Millner 2005; Keeley, Golitko 2006.

${ }^{37}$ Wahl, König 1987.
} 
mordowanych przez nieokreślony czas leżały niepochowane. Zwraca także uwagę wyraźny „niedobór” szkieletów żeńskich. Niewykluczone, że agresja napastników była skierowana przede wszystkim na mężczyzn, kobiety natomiast wzięto żywcem ${ }^{38}$.

$\mathrm{Na}$ cmentarzysku kultury ceramiki sznurowej (KCSz) w miejscowości Eulau (Niemcy) natrafiono na groby masowe, w których część szkieletów nosiła wyraźne ślady po ranach. W przeciwieństwie do przypadków z Tallheim i Schletz, zmarli z Eulau zostali pochowani zgodnie z regułami obrządku pogrzebowego oraz wyposażeni $w$ dary grobowe. Badania genetyczne wykazały, że osobników z grobów masowych łączyły więzy pokrewieństwa. Tożsamość ofiar musiała być zatem znana osobom odpowiedzialnym za organizację pochówku. Stąd przypuszczenie, że w omawianym przypadku nie doszło do wymordowania całej populacji ${ }^{39}$.

\section{Groby wojowników}

Omawiając rejestrowane archeologicznie świadectwa pradziejowych konfliktów, nie można pominąć grobów wojowników. U schyłku neolitu na obszarze Europy doszło do istotnych zmian społecznych, które zdaniem wielu badaczy ${ }^{40}$ mogły doprowadzić do instytucjonalizacji „wojny”. Zmiany te obejmowały m.in. odejście od kolektywizmu, dominującego w dotychczasowym obrządku pogrzebowym, na rzecz pochówków jednostkowych, akcentujących indywidualizm zmarłego oraz upowszechnienie się zwyczaju wyposażania niektórych pochówków męskich w broń. Reguła ta odnosi się przede wszystkim do dwóch kultur schyłkowego neolitu: kultury ceramiki sznurowej i pucharów dzwonowatych. Postępująca standaryzacja rytuału pogrzebowego, ukierunkowanego na afirmację wyidealizowanego typu męskości, związanego z posiadaniem broni i najprawdopodobniej walką, pozwala przypuszczać, że doszło wówczas do wykrystalizowania się nowej tożsamości społecznej warriorhood.

\section{Osady obronne}

Kolejną grupę znalezisk związanych z problemem „wojen” w pradziejowej Europie stanowią osady obronne. Na obszarze leżącym na północ od Alp tego typu obiekty wznoszono już w VI-V tys. BC w środowisku przedstawicieli wczesnoneolitycznych kultur rolniczych. Ich liczba jest stosunkowo wysoka - w samej tylko kulturze ceramiki wstęgowej wyróżniono blisko 60 tzw. enclosures, tj. obsza-

\footnotetext{
${ }^{38}$ Wild, Stadler et al. 2004.

${ }^{39}$ Meyer, Brandt et al. 2009.

${ }^{40}$ Sarauw 2007; Vandkilde 2006; Christensen 2004.
} 
rów grodzonych. Konstrukcje te powstawały z reguły w miejscach o zwiększonej obronności, najczęściej na wzniesieniach terenu. Założenia omawianego typu umacniano przez konstruowanie wałów, rowów i palisad. Wznoszono je również w młodszym odcinku epoki kamienia. O ich związku z działaniami zbrojnymi świadczą ślady zniszczeń, spalenizny oraz znaczna liczba grotów strzał odkrywanych na wysokości umocnień oraz bram. Na obiekcie w Crickley Hill zarejestrowano ponad 400 grotów ${ }^{41}$.

Powyższa, z konieczności bardzo skrócona, prezentacja materiałów związanych $\mathrm{z}$,wojną" w pradziejach obejmuje tylko przykłady z neolitu. Warfare w Europie ma jednak zdecydowanie starszą metrykę, o czym świadczą choćby wzmiankowane pochówki ofiar przemocy z cmentarzysk mezolitycznych (np. Teviéc, Vasylivka III, Vedbaek). Oczywiste jest, że konflikty zbrojne nie zaniknęły wraz z końcem epoki kamienia. Co więcej, radykalne zmiany społeczne, jakie przyniosła ze sobą epoka brązu, wpłynęły także na charakter ówczesnych „wojen”, nadając im nowe, bardziej skonceptualizowane oblicze ${ }^{42}$.

Badania wykopaliskowe dostarczają coraz to nowych, często ekscytujących dowodów na to, że pradziejowa Europa nie była miejscem wolnym od niepokojów (np. pole bitwy z doliny Tolensee w Meklemburgii ${ }^{43}$ ). Przyrastająca liczba materiałów związanych z ,wojną" oraz nieustanny progres dokonujący się na polu metod badawczych stwarzają zupełnie nowe możliwości dla archeologów pragnących wnieść swój wkład w rozwój badań nad problematyką warfare w pradziejach. Perspektywa ta jawi się jako szczególnie atrakcyjna dla badaczy z Polski, temat ten bowiem nie był jak dotąd szeroko dyskutowany na łamach rodzimej debaty archeologicznej.

\section{ZAKOŃCZENIE}

Opcja ,prowojenna” w archeologii przetrwała okres uśpienia i odnotowała swoisty come-back w połowie lat $90 . \mathrm{XX}$ w. Od tego czasu problematyka wojen w archeologii systematycznie zyskuje na znaczeniu. Niektóre publikacje o warfare cechuje jednak niepokojąca tendencja do gloryfikowania postaci wojowników, najczęściej utożsamianych z najwyższymi warstwami społeczeństwa. W związku z tym nadrzędne znaczenie przyznaje się przedstawicielom „klas wyższych”, marginalizując przy tym pozostałych aktorów konfliktu. Wojnie i wojownikom nierzadko przypisuje się uniwersalny, ponadczasowy wymiar. Wojownik staje się zatem sztywnym, niezmiennym konstruktem, często arbitralnie wdrażanym w przeróżne konteksty kulturowe, niekiedy o bardzo zróżnicowanej chrono- i chorologii. Przykładem

\footnotetext{
${ }^{41}$ Mercer 1999, 151-152.

${ }^{42}$ Carman 1999.

${ }^{43}$ Por. Jantzen, Brinker et al. 2011.
} 
może być chociażby próba doszukiwania się korzeni zjawiska Gefolgschaft w realiach kulturowych schyłkowego neolitu/wczesnego brązu ${ }^{44}$.

Warto również zwrócić uwagę na to, że obie konwencje badawcze - zarówno pacyfistyczna, jak i prowojenna - w gruncie rzeczy „łagodzą” wizję pradziejów, zapełniając przeszłą rzeczywistość konstruktami społecznymi reprezentującymi diametralnie różne, ale w równym stopniu wyidealizowane typy męskiej tożsamości. Uczestnicy debaty poświęconej problematyce wojen i przemocy przeważnie jedynie odtwarzają perswazyjny i dwoisty w swej wymowie „mit o prymitywnym dzikim”, opowiadając się za jedną lub drugą konwencją. Tym samym mniej bądź bardziej świadomie utrwalają pewien stereotyp poznawczy, który w dobie dynamicznie rozwijających się badań nad konfliktami zbrojnymi w pradziejach powoli traci rację bytu. Pojawianiu się nowych problemów badawczych powinien bowiem towarzyszyć nieustanny progres $\mathrm{w}$ dziedzinie tworzenia nowych, doskonalszych koncepcji teoretycznych. Bezrefleksyjne sięganie po przebrzmiałe narzędzia interpretacyjne to nie tylko anachronizm, ale wręcz podręcznikowy przejaw nieuzasadnionego epigonizmu.

Żywotność mitu upamiętniającego wyidealizowane postawy wpływa negatywnie na recepcję studiów nad warfare $\mathrm{w}$ pradziejach. Zaburza prawdziwy wymiar wojny, sprowadzając ją do roli ,igraszki” elit, służącej jedynie rozrywce i podnoszeniu prestiżu. Zadaniem współczesnej archeologii konfliktów zbrojnych jest podawanie w wątpliwość „mitów” wypaczających przebieg debaty, a nie ich bezrefleksyjne powielanie. Idealizacja postaci wojowników oraz racjonalizacja dyskursu poświęconego wojnie stanowi pewnego rodzaju barierę, którą współczesna archeologia warfare musi jak najszybciej pokonać. Kluczem do rozwiązania problemu jest przemyślana adaptacja najnowszych metod badawczych wypracowanych na gruncie nauk antropologicznych. Wzbogacają one jałowe, akademickie dyskusje o konfliktach o wątek ludzki - tj. działania, doświadczenia, motywy i emocje towarzyszące osobom uwikłanym w działania wojenne. Odczucia bólu i bezcelowości wywołane traumą wojny są, zdaniem niektórych badaczy, uniwersalne w swym charakterze ${ }^{45}$. Ludzkie cierpienie ma taki sam wymiar bez względu na to, czy mówimy o ofiarach współczesnych konfliktów, czy analizujemy przypadki wojen sprzed kilku tysięcy lat.

Przemoc, nędza i śmierć stanowią esencję wojen. Jeśli zostaną one wyłączone $\mathrm{z}$ interpretacji, nasza wizja pradziejów stanie się niekompletna, a przez to odległa od rzeczywistości. Racjonalizacja dyskursu poświęconego warfare oraz bezrefleksyjna adaptacja „mitów” promujących wyidealizowane postawy nieuchronnie prowadzą do pochwały wojen i upamiętnienia jej „,bohaterów”. Za radą H. Vandkilde powinniśmy zatem dążyć do świadomego uprawiania archeologii warfare, wolnej od stereotypów i niedomówień.

\footnotetext{
${ }^{44}$ Treherne 1995.

${ }^{45}$ Np. Tarlow 1999.
} 


\section{BIBLIOGRAFIA}

Brothwell D.

1999 Biosocial and bio-archaeological aspects of conflict and warfare [w:] Ancient Warfare. Archaeological Perspectives, red. J. Carman, A. Harding, United Kingdom, s. 25-38.

Buliński T., Kairski J. (red.)

2006 Sny, trofea, geny i zmarli. „Wojna” w spotecznościach przedpaństwowych na przyktadzie Amazonii - przeglad koncepcji antropologicznych, Poznań.

Carman J., Harding A. (red.)

1999 Ancient Warfare. Archaeological Perspectives, United Kingdom.

Carman J.

1999 Beyond the Western way of war: ancient battlefields in comparative perspective [w:] Ancient Warfare. Archaeological Perspectives, red. Carman J. Harding A., United Kingdom, s. 39-56.

Chapman J.

1999 The Origins of Warfare in the Prehistory of Central and Eastern Europe [w:] Ancient Warfare. Archaeological Perspectives, red. J. Carman, A. Harding, United Kingdom, s. $101-142$

Childe G.V.

1946 Scotland before Scots, Londyn.

1951a Man Makes Himself, Nowy Jork.

1951b Social Evolution, Londyn.

Christensen J.

2004 Warfare in the European Neolithic, Acta Archaeologica 75, s. 129-156.

Clark J.G.D., Piggot S.

1978 Prehistoric Societies, Harmodsworth.

Gat A.

2006 War in Human Civilisation, Oxford.

Gimbutas M.

1982 The Goddesses and Gods of Old Europe 6500-3500 BC. Myths and Cult Images, London.

Haas J.

$1998 \quad$ Warfare and the Evolution of Culture, Santa Fe.

Hobbes T.

1652 Lewiatan, czyli Materia, forma $i$ władza państwa świeckiego $i$ kościelnego, [2005] Warszawa.

Jantzen D., Brinker U., Orschiedt J., Heinemeier J., Piek J., Hauenstein K., Krüger J., Lidke G., Lübke H., Lampe R., Lorenz S., Schult M., Terberger T.

2011 A bronze age battlefield? Weapons and trauma in Tollense Valley, north-eastern Germany, Antiquity 85 , s. 417-433.

Keeley L.H., Golitko M.

2006 Beating ploughshares back into swords: warfare in the Linearbandkeramik, Antiquity 81, s. $312-322$.

Keeley L.H.

1996 War Before Civilisation, New York-Oxford.

Kelly R.C.

2000 Warless Societies and the Origin of War, Michigan. 
Krisitansen K., Larsson T.B.

2005 The Rise of the Bronze Age Society. Travels, Transmissions and Transformations, Cambridge, s. 108-251.

Mercer R.J.

1999 The origins of warfare in the British Isles [w:] Ancient Warfare. Archaeological Perspectives, red. J. Carman, A. Harding, United Kingdom, s. 143-157.

Meyer Ch., Brandt G., Haak W., Ganslmeier R.A., Meller H., Alt K.W.

2009 The Eulau eulogy: Bioarchaeological interpretation of lethal violence in Corded Ware multiple burials from Saxony-Anhalt, Germany, Journal of Anthropological Archaeology 28, s. 412-423.

Millner G.R.

1999 Warfare in Prehistoric and Early Historic Eastern North America, Journal of Archaeological Research 7, s. 105-151.

2005 Nineteenth-Century Arrow Wounds and Perceptions of Prehistoric Warfare, American Antiquity 70/1, s. 144-156.

Roksandic M.

2006 Violence in the Mesolithic, Documenta Praehistorica 33, s. 165-181.

Sarauw T.

2007 Male symbols or warrior identities? The ,,archery burials” of the Danish Bell Beaker Culture, Journal of Anthropological Archaeology 26, s. 65-87.

Tarlow S.

1999 Bereavement and Commemoration: An Archaeology of Mortality, Oxford.

Thorpe I.J.N.

2005 The Ancient Origins of Warfare [w:] Warfare, violence and slavery in prehistory: proceedings of a Prehistoric Society conference at Sheffield University, red. M. Parker Pearson, I.J.N. Thorpe, Oxford.

Treherne P.

1995 The Warrior's Beauty: The masculine body and self-identity in Bronze Age Europe, Journal of European Archaeology 3, s. 105-144.

Vandkilde $\mathrm{H}$

2003 Commemorative Tales. Archaeological Responses to Modern Myth, Polithics and War, World Archaeology 35, s. 126-144.

2006 Archaeology and War: Presentations of Warriors and Peasants in Archaeological Interpretations [w:] Warfare and Society. Archaeological and Social Anthropological Perspectives, red. T. Otto, H. Thrane, H. Vandkilde, Aarhus, s. 57-88.

2013 Warfare in Northern European Bronze Age Societies. Twentieth-Century Presentations and Recent Archaeological Research Inquiries [w:] The Archaeology of Violence. Interdisciplinary Approaches, red. Sarah Ralph, New York, s. 37-62.

Vencl S.

1984 War and Warfare in Archaeology, Journal of Anthropological Archaeology 3, s. $116-132$.

Wahl J., König H.G.

1987 Anthropologisch traumatologisch Unterschrung der menschlichen Skelettreste aus dem bandkeramischen Massengrab bei Talheim, Kreis Heilbronn, Funderberichte aus BadenWürtemberg 12, s. 65-193.

Wild E.M., Stadler P., Häußer A., Kutschera W., Steier P., Teschler-Nicola M.,Wahl J., Windl H.J.

2004 Neolithic Massacres: Local Skirmishes or General Warfare in Europe?, Radiocarbon 46, s. $377-385$. 


\title{
ARMED CONFLICTS IN THE PAST. RESEARCH PERSPECTIVES
}

\author{
S u m m a r y
}

The aim of this paper is to discuss the state of research on the issue of warfare and violence in prehistory and to characterize main categories of archaeological finds associated with this aspect of past human activity. Archaeology of the twentieth century, despite relatively large number/quantity of coherent data, often marginalized and underestimated the nature of problem of warfare and violence, claiming instead, that culture of prehistoric Europe was created mostly by peasants, hunters and traders, and therefore relatively peaceful. This notion was largely based on the assumption that introduction of warlike behaviour was strictly associated with the invention of writing, and thus warfare was a characteristic feature of state societies. Some researchers claim that the character of archaeological debate devoted to warfare and violence is clearly determined by the contemporary social, political and ideological situation. A significant grow in number of studies devoted to warfare has been observed since the mid-nineties of the twentieth century. This change was probably caused by widely discussed problem of ethnic wars in the Balkan region, and received little or no inspiration from contemporary anthropology of war. The main goal of a short overview of crucial categories of archaeological finds related to warfare and violence in the past is to show that large number/quantity of evidence and strong theoretical basis create great research possibilities for those who want to participate in revealing the patterns of prehistoric violence. There is no doubt that warfare constituted an important aspect of past human activity and also one of the main factors initiating cultural changes among prehistoric societies. 